Pacific Journal of Mathematics

ON THE TRANSFORMATION OF FOURIER COEFFICIENTS 


\section{ON THE TRANSFORMATION OF FOURIER COEFFICIENTS OF CERTAIN CLASSES OF FUNCTIONS}

\section{KENNETH F. ANDERSEN}

Suppose $f(x) \in L^{1}(0, \pi)$ and let $a=\left\{a_{\nu}\right\}\left(b=\left\{b_{\nu}\right\}\right)$ denote the Fourier cosine (sine) coefficients of $f$ extended to $(-\pi, \pi)$ as an even (odd) function, that is

$$
\begin{aligned}
& a_{0}=\frac{2}{\pi} \int_{0}^{\pi} f(x) d x, \quad a_{\nu}=\frac{2}{\pi} \int_{0}^{\pi} f(x) \cos \nu x d x, \\
& \quad b_{\nu}=\frac{2}{\pi} \int_{0}^{\pi} f(x) \sin \nu x d x .
\end{aligned}
$$

The sequence transformations $T$ and $T^{\prime}$ are defined by

$$
(T a)_{0}=a_{0}, \quad(T a)_{\nu}=\frac{1}{\nu} \sum_{j=1}^{\nu} a_{j}, \quad\left(T^{\prime} a\right)_{\nu}=\sum_{j=\nu}^{\infty}\left(a_{j} / j\right), \quad \nu=1,2, \cdots .
$$

The purpose of this note is to characterize those rearrangement invariant function spaces $L^{\sigma}(0, \pi)$ which are left invariant by the operators $T$ and $T^{\prime}$ acting on Fourier coefficients of functions in these spaces. Our results include and improve some results of Hardy, Bellman and Alshynbaeva.

G. H. Hardy [5] proved that if $f \in L^{p}(0, \pi)$ for some $p, 1 \leqq p<$ $\infty$, then $T a=\left\{(T a)_{\nu}\right\}$ is the sequence of Fourier cosine coefficients of a function also in $L^{p}(0, \pi)$; R. Bellman [2] proved the analogous theorem for $T^{\prime}$ except that now $1<p \leqq \infty$. Recently $\mathrm{E}$. Alshynbaeva [1] gave necessary and sufficient conditions on an Orlicz space $L_{M \Phi}$ in order that $L_{M \Phi}$ may replace the $L^{p}$ space in the results of Hardy and Bellman, thus answering a question of P. L. Ul'yanov. The analogues for the sequences $\left\{b_{\nu}\right\}$ were also studied.

We denote by $f^{*}$ the nonnegative, nonincreasing function on $(0, \pi)$ which is equi-measurable with $f$, that is, for all $\lambda>0$

$$
|\{x \in(0, \pi):|f(x)|>\lambda\}|=\left|\left\{x \in(0, \pi): f^{*}(x)>\lambda\right\}\right| .
$$

We suppose throughout that $\sigma$ is a function norm defined on the measurable functions on $(0, \pi)$ which is rearrangement invariant in the sense that $\sigma(f)=\sigma\left(f^{*}\right)$. The associate of $\sigma$, denoted $\sigma^{\prime}$, is then also rearrangement invariant and is given by

$$
\begin{aligned}
\sigma^{\prime}(f) & =\sup \left\{\left|\int_{0}^{\pi} f(x) g(x) d x\right|: \sigma(g) \leqq 1\right\} \\
& =\sup \left\{\int_{0}^{\pi} f^{*}(x) g^{*}(x) d x: \sigma(g) \leqq 1\right\} .
\end{aligned}
$$


The upper and lower Boyd indices $\alpha, \beta$ of the Banach space $L^{\sigma}(0, \pi)=$ $\{f: \sigma(f)<\infty\}$ are defined in [4] and satisfy $0 \leqq \beta \leqq \alpha \leqq 1$. For the Lorentz spaces $L^{p, q}(0, \pi)$ and in particular for the Lebesgue spaces $L^{p}(0, \pi)$, the indices $\alpha, \beta$ are both equal to $p^{-1}$. Indices for the Orlicz spaces are computed in [3]. It is well known that $L^{\infty}(0, \pi) \subseteq L^{\sigma}(0, \pi) \subseteq L^{1}(0, \pi)$ for every $\sigma$ and it is not difficult to see that $L^{p}(0, \pi) \subseteq L^{\sigma}(0, \pi) \subseteq L^{q}(0, \pi)$ whenever $p^{-1}<\beta, \alpha<q^{-1}$.

We shall state and prove our theorems only for the case of cosine coefficients $a$; for the case of sine coefficients $b$ the statements of the theorems are the same with $b$ replacing $a$ and sine, replacing cosine throughout while the proofs are similar.

Concerning the sequence $\left\{a_{\nu}\right\}$ and the transformations $T$ and $T^{\prime}$ we have the following theorems.

THEOREM 1. The following statements are equivalent.

(a) For every $f \in L^{\sigma}(0, \pi)$ with Fourier cosine coefficients $a=$ $\left\{a_{\nu}\right\}, T a$ is the sequence of Fourier cosine coefficients of a function in $L^{\sigma}(0, \pi)$.

(b) The lower index $\beta$ of $L^{\sigma}(0, \pi)$ satisfies $\beta>0$.

THEOREM 2. The following statements are equivalent.

(a) For every $f \in L^{\sigma}(0, \pi)$ with Fourier cosine coefficients $a=$ $\left\{a_{*}\right\}, T^{\prime} a$ is the sequence of Fourier cosine coefficients of a function in $L^{\sigma}(0, \pi)$.

(b) The upper index $\alpha$ of $L^{\sigma}(0, \pi)$ satisfies $\alpha<1$.

Since $\alpha=\beta=p^{-1}$ for the space $L^{p}$, Theorems 1 and 2 yield the results of Hardy and Bellman cited above. It is well known, and in any event follows easily from the formulae for $\alpha, \beta$ in [3], that for the Orlicz space $L_{M}$, the lower index $\beta$ satisfies $\beta>0$ if and only if $\Phi$ satisfies the $\Delta_{2}$ condition, i.e., $\Phi(2 t) \leqq M \Phi(t), t \geqq t_{0}$; the upper index $\alpha$ satisfies $\alpha<1$ if and only if the Young's function $\Psi$ complementary to $\Phi$ satisfies the $\Delta_{2}$ condition. Hence Theorems 1 and 2 yield Alshynbaeva's Theorems 1 and 2 with a sharpening of the necessity part of his Theorem 2 in that we do not have to assume $|t \log t| \leqq c \Phi(t), t \geqq t_{0}>0$.

We shall require the following lemma relating to the operators $P$ and $P^{\prime}$ defined for $0<x<\pi$ by

$$
(P f)(x)=\cot (x / 2) \int_{0}^{x} f(t) d t,\left(P^{\prime} f\right)(x)=\int_{x}^{x} f(t) \cot (t / 2) d t .
$$

Lemma 1. The following are equivalent.

(a) Pf $\in L^{\sigma}(0, \pi)$ for ever'y $f \in L^{\sigma}(0, \pi)$. 
(b) There is a constant c such that $\sigma(P f) \leqq c \sigma(f)$, for all $f \in$ $L^{\sigma}(0, \pi)$.

(c) The upper index $\alpha$ of $L^{\sigma}(0, \pi)$ satisfies $\alpha<1$.

(d) The lower index $\beta^{\prime}$ of $L^{\sigma^{\prime}}(0, \pi)$ satisfies $\beta^{\prime}>0$.

(e) There is a constant $c$ such that $\sigma^{\prime}\left(P^{\prime} f\right) \leqq c \sigma^{\prime}(f)$, for all $f \in L^{\sigma^{\prime}}(0, \pi)$.

(f) $P^{\prime} f \in L^{\sigma^{\prime}}(0, \pi)$ for every $f \in L^{\sigma^{\prime}}(0, \pi)$.

Proof of Lemma 1. Let $\left(P_{1} f\right)(x)=\left(\int_{0}^{x} f(t) d t\right) / x$. There are positive constants $c, c_{1}, c_{2}$ such that for all $f \geqq 0$

$$
c_{1}(P f)(x) \leqq\left(P_{1} f\right)(x) \leqq c_{2}\left((P f)(x)+\int_{0}^{\pi} f(t) d t\right) \leqq c_{2}((P f)(x)+c \sigma(f))
$$

and since $f \in L^{\sigma}(0, \pi)$ if and only if $|f| \in L^{\sigma}(0, \pi)$ it follows that (a) is equivalent to the corresponding statement with $P$ replaced by $P_{1}$; similarly $P_{1}$ may replace $P$ in (b). Analogously, $\left(P_{1}^{\prime} f\right)(x)=$ $\int_{x}^{\pi}(f(t) / t) d t$ may replace $P^{\prime}$ in statements (e) and $(f)$. Thus, it suffices to prove the lemma with $P$ replaced by $P_{1}$ and $P^{\prime}$ replaced by $P_{1}^{\prime}$ throughout. For this, the chain of implications (a) $\Rightarrow(\mathrm{b}) \Rightarrow$ (c) $\Rightarrow(d) \Longrightarrow(e)$ follows in turn from Lorentz [7, p. 486], Boyd [4, p. 1253], Boyd [4, Lemma 5] and Boyd [4, p. 1253]; (e) clearly implies (f), while if (f) holds and $f \in L^{\sigma}(0, \pi), g \in L^{\sigma^{\prime}}(0, \pi)$ with $f \geqq 0, g \geqq 0$ then Fubini's theorem shows that

$$
\int_{0}^{\pi} g(x)\left(P_{1} f\right)(x) d x=\int_{0}^{\pi} f(t)\left(P_{1}^{\prime} g\right)(t) d t \leqq \sigma(f) \sigma\left(P_{1}^{\prime} g\right)<\infty
$$

so $P_{1} f \in L^{\sigma}$ (see Lorentz [7, p. 484|) and (a) holds. This proves the lemma.

Lemma 2. If $a=\left\{a_{\nu}\right\}$ is the sequence of Fourier cosine coefficients of $f \in L^{\sigma}(0, \pi)$ then $c=\left\{c_{\nu}\right\}, c_{0}=0, c_{\nu}=a_{\nu} / \nu, \nu=1,2, \cdots$ is the sequence of Fourier cosine coefficients of a function $F \in L^{\sigma}(0, \pi)$.

Proof of Lemma 2. Let $K(t)=-\log |2 \sin (t / 2)|,|t|<\pi$. According to $[8, \mathrm{p} .180], c$ is the sequence of Fourier cosine coefficients of

$$
F(x)=\frac{1}{\pi} \int_{-\pi}^{\pi} f(x+t) K(t) d t, 0<x<\pi .
$$

Now for any $t,|t|<\pi$ we set $f_{t}(x)=f(x+t)$ and observe that since $f$ is even on $(-\pi, \pi)$, for all $\lambda>0$ 


$$
\begin{aligned}
|\{x \in(0, \pi):|f(x)|>\lambda\}| & =\frac{1}{2}|\{x \in(-\pi, \pi):|f(x)|>\lambda\}| \\
& =\frac{1}{2}\left|\left\{x \in(-\pi, \pi):\left|f_{t}(x)\right|>\lambda\right\}\right| \\
& \geqq \frac{1}{2}\left|\left\{x \in(0, \pi):\left|f_{t}(x)\right|>\lambda\right\}\right|
\end{aligned}
$$

so that $f_{t}(x)$ considered as a function on $0<x<\pi$ satisfies $\left(f_{t}\right)^{*}(x) \leqq$ $f^{*}(x / 2)$ and it then follows from (1) that $\sigma\left(f_{t}\right) \leqq 2 \sigma(f)$. Hence, if $g \in L^{\sigma^{\prime}}(0, \pi)$ with $g \geqq 0$

$$
\begin{aligned}
& \int_{0}^{\pi}|F(x)| g(x) d x \leqq \int_{-\pi}^{\pi}|K(t)| d t \int_{0}^{\pi}|f(x+t)| g(x) d x \\
& \quad \leqq \int_{-\pi}^{\pi}|K(t)| \sigma\left(f_{t}\right) \sigma^{\prime}(g) d t \leqq 2 \sigma(f) \sigma^{\prime}(g) \int_{-\pi}^{\pi}|K(t)| d t
\end{aligned}
$$

so that upon taking the supremum over $g \in L^{\sigma^{\prime}}(0, \pi)$ with $g(x) \geqq 0$, $\sigma^{\prime}(g) \leqq 1$ it follows that $\sigma(F) \leqq 2 \sigma(f) \int_{-\pi}^{\pi}|K(t)| d t<\infty$. Thus $F \in$ $L^{\sigma}(0, \pi)$ and the lemma is proved.

Since $L^{\sigma}(0, \pi)$ contains all the constant functions, we may assume without loss of generality that $a_{0}=0$ in the proofs of Theorem 1 and 2.

Proof of Theorem 1. As Hardy [5] has shown, $T a$ is the sequence of Fourier cosine coefficients of $g(x)=\left(P^{\prime} f(x)+F(x)\right) / 2$, where $F$ is given by Lemma 2. Thus, if (a) holds, Lemma 2 shows that we must have $P^{\prime} f \in L^{\sigma}(0, \pi)$ whenever $f \in L^{\sigma}(0, \pi)$ and then Lemma 1 shows that $\beta>0$ so (b) holds. Conversely, if (b) holds, Lemma 1 shows that $P^{\prime} f \in L^{\sigma}(0, \pi)$ while Lemma 2 shows that $F \in$ $L^{\sigma}(0, \pi)$ so that $g \in L^{\sigma}(0, \pi)$ and (a) holds. This proves the theorem.

Proof of Theorem 2. Suppose first that (a) holds and $f \in L^{\circ}(0, \pi)$. Let $o$ be such that $\int_{0}^{\delta} f^{*}(x) d x=\frac{1}{2} \int_{0}^{\pi}|f(x)| d x, 0<\delta<\pi$, and set

$$
g(x)=\left\{\begin{array}{rll}
f^{*}(x) & \text { if } & 0<x<\delta \\
-f^{*}(x) & \text { if } & \delta<x<\pi
\end{array}\right.
$$

Clearly $g \in L^{\sigma}(0, \pi), g(x)$ is nonnegative, nonincreasing on $(0, \delta)$, and $\int_{0}^{\pi} g(x) d x=0$. Let $a^{\sharp}=\left\{a_{\nu}^{\sharp}\right\}$ denote the Fourier cosine coefficients of $g(x)$. Since $g \in L^{\sigma}(0, \pi)$ and (a) holds, it follows that $\left(T^{\prime} a^{\sharp}\right)_{1}=\sum_{j=1}^{\infty}\left(a_{j}^{\sharp}\right) / j$ converges, and according to Loo [6, p. 273]

$$
\left(T^{\prime} a^{\sharp}\right)_{1}=\lim _{N \rightarrow \infty} \frac{1}{\pi} \int_{0}^{\pi}(1-\cos N x)(P g)(x) d x .
$$

But then since $(P g)(x)$ is integrable on $(\delta, \pi)$ the Riemann Lebesgue 
lemma guarantees the existence of

$$
\lim _{N \rightarrow \infty} \int_{0}^{o}(1-\cos N x)(P g)(x) d x .
$$

Now, $(P g)(x)$ nonincreasing on $(0, \delta)$ shows

$$
\begin{aligned}
\lim _{N \rightarrow \infty} \int_{0}^{o}(1-\cos N x)(P g)(x) d x & \geqq \lim _{N \rightarrow \infty} \sum_{k=1}^{\left[\frac{N o}{2 \pi}\right]}(P g)\left(\frac{2 k \pi}{N}\right) \frac{1}{\pi} \int_{2(k-1) \pi / N}^{2 k \pi / N}(1-\cos N x) d x \\
& =\frac{1}{\pi} \lim _{N \rightarrow \infty} \frac{2 \pi}{N} \sum_{k=1}^{\left[\frac{N o}{2 \pi}\right]}(P g)\left(\frac{2 k \pi}{N}\right) \\
& =\frac{1}{\pi} \int_{0}^{o}(P g)(x) d x \\
& =\frac{2}{\pi} \int_{0}^{o} g(t) \log \left|\frac{\sin (\delta / 2)}{\sin (t / 2)}\right| d t .
\end{aligned}
$$

It follows that $|g(t)| \log ^{+}(1 / t)$ is integrable on $(0, \pi)$ and hence $[6, p$. 273] $T^{\prime} a^{\sharp}$ is the sequence of Fourier cosine coefficients of $H(x)=$ $((P g)(x)+G(x)) / 2$ where $G$ is the function associated by Lemma 2 to the sequence $a^{\sharp}$. Since $G \in L^{\sigma}(0, \pi)$ for any $\sigma$, and $H \in L^{\sigma}(0, \pi)$ by hypothesis, it follows that $P g \in L^{\sigma}(0, \pi)$. Now, since $|(P f)(x)| \leqq$ $(P|g|)(x)$ it follows that $P f \in L^{\sigma}(0, \pi)$ whenever $f \in L^{\sigma}(0, \pi)$ so then Lemma 1 shows $\alpha<1$. Thus (a) implies (b).

Conversely, suppose (b) holds. There is a number $p>1$ such that $\alpha<p^{-1}$ so $L^{\sigma}(0, \pi) \subset L^{p}(0, \pi)$ and hence if $f \in L^{\sigma}(0, \pi)$ Hölder's inequality shows $\int_{0}^{\pi}|f(t)| \log ^{+}(1 / t) d t<\infty$. According to Loo [6, p. 273-274] $T^{\prime} a$ is then the sequence of Fourier cosine coefficients of $h(x)=(P f(x)+F(x)) / 2$ where $F$ is the function of Lemma 2. Now Lemma 1 shows that $\operatorname{Pf} \in L^{\sigma}(0, \pi)$ and hence $h \in L^{\sigma}(0, \pi)$ so (a) holds. The theorem is proved.

\section{REFERENCES}

1. E. Alshynbaeva, Transformations of Fourier coefficients of certain classes of functions, Math. Notes, 25 (1979), 332-335.

2. R. Bellman, $A$ note on a theorem of Hardy on Fourier coefficients, Bull. Amer. Math. Soc., 50 (1944), 741-744.

3. D. W. Boyd, Indices for the Orlicz spaces, Pacific J. Math., 38 (1971), 315-323.

4. - Indices of function spaces and their relationship to interpolation, Canad.

J. Math., 21 (1969), 1245-1254.

5. G. H. Hardy, Notes on some points in the integral calculus LXVI, Messenger Math.. 58 (1928), 50-52.

6. C.-T. Loo, Notes on the properties of Fourier coefficients, Amer. J. Math., 71 (1949), 269-282.

7. G. G. Lorentz, Majorants in spaces of integrable functions, Amer. J. Math., 77 (1955), 484-492. 
8. A. Zygmund, Trigonometric Series, Vol I and II combined, Cambridge Univ. Press, 1968.

Received May 21, 1980. Research supported in part by NSERC grant \#A-8185.

UNIVERSITY OF ALBERTA

Edmonton, Alberta, Canada 


\section{PACIFIC JOURNAL OF MATHEMATICS}

\section{EDITORS}

DONALD BABBITT (Managing Editor)

University of California

Los Angeles, CA 90024

Hugo RossI

University of Utah

Salt Lake City, UT 84112

C. C. Moore and Arthur Agus

University of California

Berkeley, CA 94720
J. DugundJI

Department of Mathematics

University of Southern California

Los Angeles, CA 90007

R. FinN and J. MiLgRAM

Stanford University

Stanford, CA 94305

\section{ASSOCIATE EDITORS}
R. ARENS
E. F. BECKENBACH
B. H. NeumanN
F. WOLF
K. YoSHIDA

\section{SUPPORTING INSTITUTIONS}

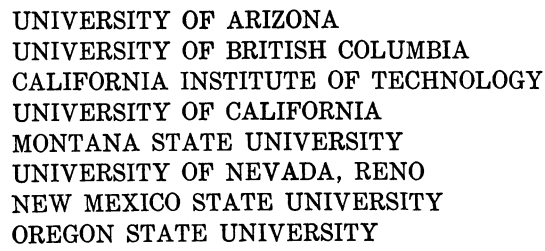

UNIVERSITY OF ARIZONA

UNIVERSITY OF BRITISH COLUMBIA CALIFORNIA INSTITUTE OF TECHNOLOGY UNIVERSITY OF CALIFORNIA MONTANA STATE UNIVERSITY

UNIVERSITY OF NEVADA, RENO NEW MEXICO STATE UNIVERSITY OREGON STATE UNIVERSITY

\author{
UNIVERSITY OF OREGON \\ UNIVERSITY OF SOUTHERN CALIFORNIA \\ STANFORD UNIVERSITY \\ UNIVERSITY OF AAWAII \\ UNIVERSITY OF TOKYO \\ UNIVERSITY OF UTAH \\ WASHINGTON STATE UNIVERSITY \\ UNIVERSITY OF WASHINGTON
}

The Supporting Institutions listed above contribute to the cost of publication of this Journal, but they are not owners or publishers and have no responsibility for its content or policies,

Mathematical parers intended for publication in the Pacific Journal of Mathematics should be in typed form or offset-reproduced, (not dittoed), double spaced with large margins. Please do not use built up fractions in the text of the manuscript. However, you may use them in the displayed equations. Underline Greek letters in red, German in green, and script in blue. The first paragraph or two must be capable of being used separately as a synopsis of the entire paper. Please propose a heading for the odd unmbered pages of less than 35 characters. Manuscripts, in triplicate, may be sent to any one of the editors. Please classify according to the scheme of Math. Reviews, Index to Vol. 39. Supply name and address of author to whom proofs should be sent. All other communications should be addressed to the managing editor, or Elaine Barth, University of California, Los Angeles, California, 90024 .

50 reprints to each author are provided free for each article, only if page charges have been substantially paid. Additional copies may be obtained at cost in multiples of 50 .

The Pacific Journal of Mathematics is issued monthly as of January 1966, Regular subscription rate: $\$ 114.00$ a year (6 Vol., 12 issues). Special rate: $\$ 57.00$ a year to individual members of supporting institution.

Subscriptions, orders for numbers issued in the last three calendar years, and changes of address shoud be sent to Pacific Journal of Mathematics, P.O. Box 969, Carmel Valley, CA 93924, U.S.A. Old back numbers obtainable from Kraus Periodicals Co., Route 100, Millwood, NY 10546.

\section{PUBLISHED BY PACIFIC JOURNAL OF MATHEMATICS, A NON-PROFIT CORPORATION}

Printed at Kokusai Bunken Insatsusha (International Academic Printing Co., Ltd.). 8-8, 3-chome, Takadanobaba, Shinjuku-ku, Tokyo 160, Japan.

Copyright (C) 1982 by Pacific Journal of Mathematics Manufactured and first issued in Japan 


\section{Pacific Journal of Mathematics}

Vol. 100, No. $2 \quad$ October, 1982

Kenneth F. Andersen, On the transformation of Fourier coefficients of

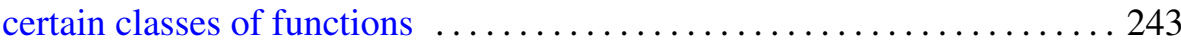

Steven Albert Bleiler, Realizing concordant polynomials with prime knots

Reinhard Bürger, Functions of translation type and solid Banach spaces of functions

Ulrich Daepp, The saturation of $k$-analytic rings and topological equivalence of associated analytic set germs .................. 271

Persi W. Diaconis and David Amiel Freedman, On the maximum difference between the empirical and expected histograms for sums . . . 287

David Amiel Freedman, On the maximum of scaled multinomial

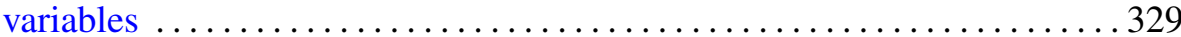

Persi W. Diaconis and David Amiel Freedman, On the difference between the empirical histogram and the normal curve, for sums. II ......... 359

Persi W. Diaconis and David Amiel Freedman, On the mode of an

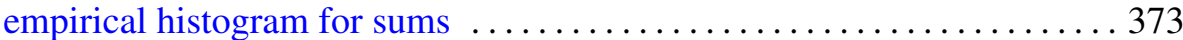

Jutta Hausen, Supplemented modules over Dedekind domains 387

Elyahu Katz, A moduli representation for the classification of twisted tensor

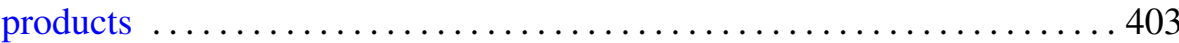

H. C. Madhekar and N. K. Thakare, Biorthogonal polynomials suggested by the Jacobi polynomials

Ted R. Pettis, Collections of covers of metric spaces 425

Ryōtarō Satō, Maximal functions for a semiflow in an infinite measure space

Michael Jay Stob, Invariance of properties under automorphisms of the lattice of recursively enumerable sets 